\title{
TAREFAS FUNDAMENTAIS NO FAZER MATEMÁTICO ESCOLAR: ORGANIZAÇÃO MATEMÁTICA PARA O ENSINO DA GEOMETRIA ANALÍTICA
}

\author{
Renato Borges GUERRA ${ }^{1}$ \\ Universidade Federal do Pará \\ rguerra@ufpa.br
Roberto Carlos Dantas ANDRADE
Universidade Federal do Pará dantasprof@ig.com.br

\begin{abstract}
Resumo: Este trabalho é parte de uma pesquisa realizada no Instituto de Educação Matemática e Científica (IEMCI), da Universidade Federal do Pará (UFPA), em que fazemos uma reflexão acerca das tarefas para o estudo da Geometria Analítica Plana, presentes nas organizações didáticas de livros e textos adotados no ensino médio, de forma a identificar as relações existentes entre elas, em busca de evidenciar tarefas mais inclusivas, denominadas por nós de tarefas fundamentais, que articuladas subsidiam a resolução de outras tarefas e a partir deste tipo de tarefas propor uma organização matemática que possa contribuir para as organizações didáticas-matemáticas de professores de tal forma a possibilitar um fazer matemático escolar caracterizado por um fazer inteligível e justificado. Isso é realizado à luz da Teoria Antropológica do Didático (TAD).
\end{abstract}

Palavras-chave: Geometria Analítica. Praxeologia. Tarefas Fundamentais.

Abstract: This essay is part of a research held at the Scientific and Mathematical Education Institute, in Federal University of Pará (UFPA), in which we make a reflection over the tasks for the study of the Plane Analytical Geometry contained in didatics text books adopted in Highschool (Medium Educational Level) in order to identify the relationship among them aiming to determine more inclusive tasks, called by us as "fundamental tasks" which, related to one another, are the base for the solution of other tasks. And, based on this kind of task, propose a new

\footnotetext{
${ }^{1}$ Doutor, docente do Programa de Pós-graduação de Educação em Ciências e em Matemáticas (IEMCI/UFPA).

${ }^{2}$ Professor Mestre e Doutorando do Programa de Pós-graduação de Educação em Ciências e em Matemáticas (IEMCI/UFPA).
} 
mathematical organization that may contribute to the teachers' mathematicaldidatics organization as to allow a "school mathematics practice" characterized by a justified and understandable practice. This is accomplished having the Didatics Antropological Theory as a reference.

Keywords: Anlytical Geometry. Praxiology. Fundamental Tasks.

\section{Introdução}

Todo profissional, como um professor de matemática, por exemplo, tem necessidades de poder atuar mais e melhor e também de maneira justificada e inteligível. Essa necessidade nos orienta no sentido de identificar e reorganizar os temas de estudo para que possa tornar as aulas mais significativas para os alunos, de tal forma a orientá-los na construção de seus conhecimentos sobre os objetos matemáticos.

Nesse sentido, buscamos nesse trabalho, propor uma reflexão acerca das tarefas, sobre Geometria Analítica Plana, presentes nos livros textos adotados no ensino médio, de forma a identificar as relações existentes entre elas, destacando o que denominamos de tarefas fundamentais, e desse modo fornecer subsídios para uma (re)organização didática e matemática para o ensino-aprendizagem desse tema.

Para isso recorremos à Teoria Antropológica do Didático, concebida por Yves Chevallard, que possibilita identificar elementos de uma organização matemática, como os níveis do saber fazer (tarefas e técnicas) e do saber (tecnológico e teórico), os quais permitem analisar uma organização didática, tanto no que diz respeito a sua construção quanto da sua efetiva aplicação em sala de aula.

1 Teoria Antropológica do Didático (TAD) como referencial para a construção de uma organização didática de Geometria Analítica Plana

A TAD, concebida na França, em meados dos anos noventa, por Yves Chevallard, enfatiza três tipos de atividades: as estritamente humanas, as estritamente institucionais e as humanas reguladas por critérios institucionais as quais podem ser exemplificadas, respectivamente, como sendo o ato de tomar água, emitir uma certidão de nascimento e ministrar aula de Matemática. 
Nas do terceiro tipo, as atividades humanas reguladas por critérios institucionais, como a exemplificada acima, no ato de ministrar aula de Matemática, o professor tem a liberdade de escolha do objeto de ensino, porém esta escolha é vinculada a alguns critérios que devem ser considerados, como a série ou a faixa etária dos alunos, a matriz curricular da instituição e outros. Sendo assim, quando ocorre a construção da organização didática, no caso a organização matemática escolhida, é necessário considerar o conjunto de regras e normas estabelecidas pelas instituições escolares, no sentido de regular a atividade. São esses tipos de situações que caracterizam as atividades humanas e das instituições sociais, ou seja, o conectivo $e$ significa estar na intersecção entre as atividades estritamente humanas e as atividades estritamente institucionais. É no conjunto das atividades humanas e das instituições sociais que se localizam as atividades matemáticas o que, segundo Chevallard (2002 apud ALMOULLOUD, 2000), é um dos princípios fundamentais da TAD.

Com a designação antropológica dada a essa teoria, Chevallard quer destacar que um saber é relativo a uma determinada instituição, na qual vive com características específicas. O autor caracteriza fundamentalmente três elementos: o sistema didático, como marco sistemático de referência à análise; a noção praxeológica, como marco conceitual que estrutura a noção de saber; a transposição didática, como teoria que abarca os fenômenos de trânsito do saber entre instituições.

A didática da Matemática, na perspectiva da TAD, é posta como o estudo do homem (ou das sociedades) aprendendo, ensinando e pesquisando Matemática. Como uma atividade humana, pode ser modelada nos termos de praxeologias, chamadas de Praxeologias Matemáticas ou Organizações Matemáticas, que proporcionam um método de descrição e análise das práticas institucionais e o estudo das condições das mesmas. Dessa forma, assume-se a praxeologia matemática como uma organização matemática vivenciada que permita aos alunos atuarem com eficácia para resolver problemas e, ao mesmo tempo, entendam o que fazem de maneira racional. Nesse sentido, de uma maneira simplificada, pode-se dizer que o que aprendemos e ensinamos em uma instituição educacional são praxeologias matemáticas.

É imprescindível destacar que na perspectiva da TAD, tanto o matemático pesquisador como os alunos de Matemática, cada qual em seu nível, utilizam técnicas didáticas como instrumentos para construir uma praxeologia matemática. Já o professor utiliza técnicas didáticas para

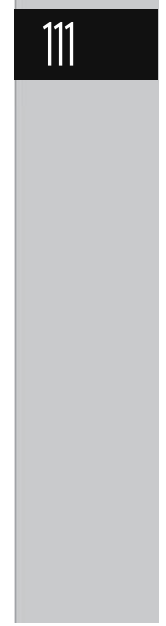


reorganizar certas obras matemáticas, de modo que dêem resposta às questões que os alunos apresentam. Nesse sentido, Rossini afirma que:

Essa teoria permite abordar a complexidade que envolve a prática profissional do professor, que se encontra diante do problema de reconstruir as organizações matemáticas que aparecem nos programas oficiais e nos livros didáticos ao preparar um determinado tema para o ensino e aprendizagem em sala de aula. Cabe ao professor construir organizações didáticas tendo por objetivo proporcionar condições favoráveis para aprendizagens das organizações matemáticas em estudo (ROSSINI, 2005, p. 2).

Ao refletir sobre a TAD e ao concordar com o exposto acima, percebe-se a relevância desta teoria para poder desenvolver e analisar organizações didáticas que venham a atender nossas inquietações no ensino-aprendizagem da Geometria Analítica.

Nessa perspectiva, analisamos uma organização didática para o ensino-aprendizagem deste tema a fim de (re)construir uma nova praxeologia por meio da reorganização de uma obra matemática. Para Chevallard et al. (2001), ao analisar as relações entre prática e teoria descritas em toda atividade, inclusive na atividade matemática, constatou duas partes que vivem em simultaneidade. De um lado, estão as tarefas e as técnicas que eles denominam de prática, ou do grego práxis, e do outro, as tecnologias e teorias as quais, segundo os autores, os gregos denominaram de logos. O logos é composto de elementos que possibilitam a justificativa e o entendimento do que é feito, ou seja, é o domínio do discurso fundamentado sobre a prática. No entanto, a relação entre praxis e logos é estreita e "[...] não há práxis sem logos, mas que também não há logos sem práxis. As duas estão unidas como dois lados de uma folha de papel. Quando juntamos as palavras gregas práxis e logos, encontramos a palavra praxeologia” (CHEVALLARD et al. 2001, p. 251).

A tênue fronteira entre práxis e logos parece decorrer dessa interdependência e a diferença, em algum momento, pode ser apenas de ordem funcional. Com isso salientamos o caráter integrador entre práxis e logos no fazer matemático escolar, isto é, como uma ação articulada e integrada de tarefas para a consecução de outras. Sob essa hipótese, no desenvolvimento do processo de estudo de um objeto matemático, podemos ver uma tarefa como uma articulação integrada de outras tarefas 
e com isso inferir a existência de tarefas primeiras, ou mais inclusivas em relação às demais, que denominamos de tarefas fundamentais.

Dessa forma, podemos (re)organizar as tarefas de uma praxeologia já existente de modo a poder atuar mais e melhor, de maneira justificada e inteligível. Isto nos orienta no sentido de identificar e reorganizar praxeologias para que possam tornar as aulas, que envolvem o objeto matemático, mais significativas para os alunos, de tal forma a orientálos na construção de suas próprias praxeologias. É isto que se buscou, neste trabalho, por meio de uma reflexão sobre as tarefas presentes nos livros-textos adotados no ensino médio, de forma a identificar as relações existentes entre elas e desse modo proporcionar uma (re)organização didática e matemática para o ensino-aprendizagem da Geometria Analítica.

\section{Tarefas Fundamentais}

Ao que propõe Chevallard et al. (2001) quanto à distinção entre técnica, tecnologia e teoria, Miguel (2005) descreve que esta diferença é de ordem funcional e deve sempre se referir ao tipo de tarefas que se toma como ponto de referência. Para a autora, no âmbito da tecnologia, situam-se os conceitos e as noções que permitem compreender e controlar a atividade humana; nele, objetos ostensivos são manipulados concretamente para permitir materializar explicações e justificativas necessárias ao desenvolvimento da técnica; a teoria é a especulação abstrata da tecnologia. No plano teórico estão as definições, os teoremas, as noções mais abrangentes e abstratas que servem para explicar, justificar e produzir tecnologias. Cria-se, então, o bloco teórico-tecnológico associado ao saber.

Assim, a rede constituída dos blocos saber-fazer e saber é complexa, visto que a distinção entre técnica, tecnologia e teoria pode em algum momento ser apenas de ordem funcional. Nesse entendimento, um novo tipo de tarefas pode requerer os enfrentamentos de outros tipos, que por sua vez requerem técnicas que podem se constituir em tecnologias para as novas técnicas desse novo tipo de tarefas. Nessa complexidade de relações, elegemos as tarefas que denominamos de fundamentais que se caracterizam pelas articulações entre si para a consecução de outras tarefas do processo de estudo e que, sem dúvida, evidenciam o desejado fazer justificável e inteligível que deve caracterizar o fazer matemático escolar.

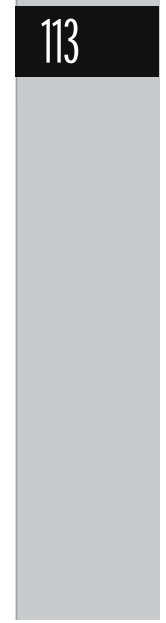


Nesse sentido, buscamos identificar os tipos de tarefas presentes nas organizações matemáticas, apresentadas nas organizações didáticas, nas edições disponibilizadas em 2009, dos livros-textos do ensino médio: Matemática volume único para o ensino médio (YOUSSEF, 2005) e Matemática volume único (DANTE, 2005), recomendados pelo Programa Nacional do Livro para o Ensino Médio/PNLEM.

As organizações didáticas propostas nos livros apresentam objetos matemáticos como: ponto, reta, circunferência e cônicas sem conexões explícitas. Tratam do tema em cinco blocos isolados denominados de estudo do ponto, estudo da reta, continuação do estudo da reta, estudo da circunferência e estudo das cônicas. Nossa análise teve como foco os tipos de tarefas tendo certo destaque dentro de cada bloco da organização, como descritos na tabela a seguir.

\section{Esquema da Organização Didática Presente nos Livros} Analisados

\begin{tabular}{|c|c|c|c|c|}
\hline Bloco 1 & Bloco 2 & Bloco 3 & Bloco 4 & Bloco 5 \\
\hline $\begin{array}{c}\text { Estudo do } \\
\text { ponto }\end{array}$ & $\begin{array}{c}\text { Estudo da } \\
\text { reta }\end{array}$ & $\begin{array}{c}\text { Continuação } \\
\text { do estudo da } \\
\text { reta }\end{array}$ & $\begin{array}{c}\text { Estudo da } \\
\text { circunferência }\end{array}$ & $\begin{array}{c}\text { Estudo das } \\
\text { cônicas }\end{array}$ \\
\hline $\begin{array}{c}\text { Localizar } \\
\text { pontos no } \\
\text { plano }\end{array}$ & $\begin{array}{c}\text { Analisar a } \\
\text { inclinação da } \\
\text { reta }\end{array}$ & $\begin{array}{c}\text { Encontrar a } \\
\text { equação da } \\
\text { reta dado dois } \\
\text { pontos }\end{array}$ & $\begin{array}{c}\text { Encontrar a } \\
\text { equação da } \\
\text { circunferência }\end{array}$ & $\begin{array}{c}\text { Encontrar a } \\
\text { equação da } \\
\text { elipse }\end{array}$ \\
\hline $\begin{array}{c}\text { Calcular a } \\
\text { distância } \\
\text { entre dois } \\
\text { pontos }\end{array}$ & $\begin{array}{c}\text { Determinar } \\
\text { o coeficiente } \\
\text { angular }\end{array}$ & $\begin{array}{c}\text { Analisar } \\
\text { a posição } \\
\text { relativa entre } \\
\text { duas retas }\end{array}$ & $\begin{array}{c}\text { Encontrar a } \\
\text { equação da } \\
\text { hipérbole }\end{array}$ \\
\hline $\begin{array}{c}\text { Determinar } \\
\text { o ponto } \\
\text { médio de um } \\
\text { segmento }\end{array}$ & $\begin{array}{c}\text { Encontrar a } \\
\text { equação da } \\
\text { reta dado } \\
\text { um ponto e } \\
\text { o coeficiente } \\
\text { angular }\end{array}$ & $\begin{array}{c}\text { Calcular o } \\
\text { angulo entre } \\
\text { duas retas }\end{array}$ & & $\begin{array}{c}\text { Encontrar a } \\
\text { equação da } \\
\text { parábola }\end{array}$ \\
\hline $\begin{array}{c}\text { Analisar as } \\
\text { condições } \\
\text { em que três } \\
\text { pontos estão } \\
\text { alinhados }\end{array}$ & $\begin{array}{c}\text { Calcular a } \\
\text { distância entre } \\
\text { ponto e reta }\end{array}$ & & & \\
\hline
\end{tabular}


Nesta organização, os dois primeiros blocos, estudo do ponto e estudo da reta, são apresentados sem evidenciar, explicitamente, conexões entre as tarefas presentes neles, exceto tímidas conexões entre as tarefas do mesmo bloco, mais marcantes no segundo bloco. Há apresentação direta da condição (fórmula) que estabelece o alinhamento de três pontos.

Após o estudo destes dois blocos, a organização didática apresenta o terceiro bloco que trata da continuação do estudo da reta sem explicitar conexões existentes com os blocos anteriores. As conexões existentes são deixadas como interpretação para o leitor, como por exemplo, no tipo de tarefas encontrar a equação geral da reta dado dois pontos, no qual se aplica a técnica do cálculo do determinante, sem referenciar a condição de alinhamento de três pontos tratado no primeiro bloco. Em seguida, apresenta-se o próximo tipo de tarefas, analisar a posição relativa entre duas retas, propondo como técnica o uso do coeficiente angular, mais uma vez sem explicitar de forma enfática a conexão existente entre estes tipos de tarefas, apesar do resgate do coeficiente angular.

Ainda no enfoque do estudo da reta, são apresentadas as tarefas do tipo, determinar os ângulos entre duas retas, as quais se estabelece como técnica a tangente do ângulo entre elas, a partir da apresentação da expressão $\operatorname{g} \theta=\frac{m_{1}-m_{2}}{1+m_{1} m_{2}}$. O último tipo de tarefas desse terceiro bloco é calcular a distância entre ponto e reta, em que é apresentada de forma direta a expressão $d_{\mathbb{p}}=\left|\frac{\mathbb{a}_{0}+{ }_{0},+c}{\sqrt{a^{2}+b^{2}}}\right|$. Este terceiro bloco, além de está majoritariamente desconectado dos outros dois anteriores, é marcado por apresentação direta de técnicas para tarefas, embaçando as possíveis conexões que poderiam ser vislumbradas pelo aluno no processo estudo. Explicitamente, a ênfase é no saber-fazer (tarefa, técnica) que, embora necessário, não constitui o saber, ou ainda o desejado fazer justificável.

Os dois outros blocos tratam das cônicas com destaque para o estudo da circunferência que ganha um bloco dedicado. Neste, é apresentado o tipo de tarefas, encontrar a equação da circunferência, por meio 
da técnica da distância entre dois pontos, ou seja, distância entre o ponto que designa o centro $\mathbf{c}(\mathbf{a}, \mathbf{b})$ da circunferência e um ponto $\mathbf{p}(\mathbf{x}, \mathbf{y})$ qualquer da circunferência. A conexão com a tarefa distância entre dois pontos, do primeiro bloco, embora explícita, não é explorada. É direta, podendo até ser despercebida. Novamente a ênfase é no saber-fazer (tarefa, técnica).

O último bloco de tipos de tarefas apresentado é o da equação das cônicas, sendo este totalmente desconectado dos outros e, até dentro dele, as equações são apresentadas a partir de expressões gerais que devem servir de modelos para os alunos, destacando elementos característicos de cada cônica. Esses modelos são usados para o enfrentamento de tipos de tarefas como: Encontrar a Equação da elipse, Encontrar a Equação da hipérbole e Encontrar a Equação da parábola. Este bloco também apresenta a definição das cônicas por meio de distâncias entre pontos, porém esta tarefa não é evidenciada de modo a prover ao aluno um fazer justificado de articulações e integrações de tipos de tarefas já estudadas.

Enfim, podemos perceber, a partir dessas análises das organizações didáticas, que a praxeologia matemática assumida nos livros, quando evidencia conexão, esta é posta, em nossa opinião, de modo tímido, não evidenciando as possíveis articulações e integrações que podem ser realizadas entre os tipos de tarefas propostas ao longo do processo de estudo. No entanto, essa análise nos permite eleger tipos de tarefas que podem estar ora mais, ora menos, presentes em todas as outras, por meio de articulações implícitas ou explícitas entre si. Tais articulações entre esses tipos de tarefas, ditas fundamentais (TTF), no decorrer do processo de estudo, pode prover um fazer inteligível e justificado e proporcionar um olhar para geração de novas praxeologias matemáticas.

Assim, os tipos de tarefas identificadas em nossa pesquisa como fundamentais para promover os momentos didáticos de um processo de estudo da Geometria Analítica são:

Tipos de Tarefa fundamental 1 (TTF1): Localizar um ponto no plano.

Tipos de Tarefa fundamental 2 (TTF2): Calcular a distância entre dois pontos dados.

Tipo de Tarefa fundamental 3 (TTF3) : Encontrar a equação do segmento $\bar{B}$. 
A partir destes três tipos de tarefas, os quais denominamos de tipos de tarefas fundamentais (TTF), ou seja, tarefas que propiciam a manifestação e conexões de outros tipos de tarefas (TT), que neste estudo compõem as organizações matemáticas presentes nos livros didáticos, utilizados pelos docentes para a elaboração de suas organizações didáticamatemática, para o estudo da Geometria Analítica. Dessa forma, passamos a evidenciar as articulações e integrações dos TTF presentes em um tipo de tarefa.

\section{Tarefas Evocadas e Articuladas pelas Tarefas Fundamentais}

Objetivando evidenciar a hipótese de que as tarefas fundamentais fazem emergir outras tarefas propostas para o ensino da Geometria Analítica, no nível médio, serão utilizados os principais tipos de tarefas apresentados nos livros-textos, neste nível de ensino, os quais podemos verificar que em geral são apresentados desconectados uns dos outroas. Assumindo que qualquer tarefa necessariamente partirá da TTF1 (Localizar de pontos no plano). Serão consideradas, para realização das tarefas a seguir, apenas as que complementam esta.

Tipos de Tarefas I (TT1): Determinar em que condição três pontos são colineares.

A realização desse tipo de tarefas requer a TTF3 (encontrar a equação do segmento).

Tipos de Tarefas II (TT2): Encontrar a equação da reta dados dois pontos que pertencem a mesma.

Para realizar esse tipo de tarefas teremos de recorrer à tarefa fundamental TTF3.

Tipos de Tarefas III (TT3): Verificar a posição relativa entre duas retas dadas.

Essa tarefa poderá ser realizada manipulando a TTF2 (calcular a distância entre dois pontos) combinada com a TTF3.

Tipos de Tarefas IV(TT4): Encontrar equação da reta $s$ que passa por um ponto $P$ e é perpendicular a reta $r$. 
Essa tarefa requer a articulação da TTF3 com a TT3.

Tipos de Tarefas V(TT5): Calcular a distância entre um ponto $P\left(x_{,}\right.$ $\left.y_{0}\right)$ na reta $r$ de equação $a x+b y+c=0$.

Na realização da TT5 devem-se articular tipos de tarefas como: a TT4; encontrar o ponto $\{\mathrm{Q}\}=\mathrm{r} \cap \mathrm{s}$ (resolver o sistema); a TTF2: Encontrar e calcular a distância entre os pontos $\mathrm{P}$ e Q.

Tipos de Tarefas VI (TT6): Se três pontos assinalam os vértices de triângulo, como calcular a área desse triângulo?

O TT6 é solucionado pela combinação da TTF2 e da TT5, porém a técnica apresentada nos livros didáticos é a resolução de um determinante, esta técnica é proposta de forma totalmente desconectada de outras tarefas, o que nos permite destacar que o simples uso de um determinante no cálculo de áreas de triângulos obscurece o fazer matemático de onde, não raro, se origina questões de alunos - e até mesmo de docentes - do tipo "O que tem a ver esse determinante com a área? Que mágica é essa?"

Tipos de Tarefas VII (TT7): Encontrar a equação do lugar geométrico dos pontos $P$ do plano cartesiano cuja soma das distâncias a dois pontos fixos $e$ distintos $F_{1}$ e $F_{2}$, e distintos de $P$, é igual a $2 a$ e maior que a distância $2 c$ entre eles. E lipse $={ }^{n} \in \alpha_{1}^{\prime, \bar{n}}+\overline{{ }^{n}}=2$ a $\}$.

Excetuando tarefas outras do ensino fundamental, as tarefas articuladas estão restritas ao TTF2 (distância entre dois pontos).

Tipos de Tarefas VIII (TT8): Encontrar a equação do lugar geométrico dos pontos $P$ do plano cartesiano, cuja diferença entre as distâncias entre esse ponto a dois pontos distintos $F_{1}$ e $F_{2}$, também distintos de $P$, é igual a 2 a e é menor que a distância $2 c$ entre eles. H ip é rb o le $\left.={ }^{\mathrm{rn}} \in \alpha^{\prime}, \overline{{ }^{n},}, \overline{{ }^{n},}=2 \mathrm{a}\right\}$.

Excetuando tarefas outras do ensino fundamental, as tarefas articuladas estão restritas ao TTF2.

Tipos de Tarefas IX (TT9): Encontrar a equação do lugar geométrico dos pontos $P$, do plano cartesiano, cuja distancia a um ponto $C$ dado é igual a $r$, ou ainda, "encontrar a equação da circunferência de centro $C(a, b)$ e raio $r$ ".

Excetuando tarefas outras do ensino fundamental, as tarefas articuladas estão restritas ao TTF2. 
Como se observa, as tarefas aqui apresentadas são produtos da articulação das tarefas fundamentais, localizar pontos no plano, calcular distância entre dois pontos e encontrar a equação do segmento, com destaque para a presença constante do cálculo da distância entre dois pontos, e é nesse sentido que são destacadas como tarefas fundamentais. Neste trabalho, não queremos afirmar que outras tarefas são levadas a cabo somente por meio dessas tarefas/técnicas, mas destacar que é possível e desejável explicitar essas articulações, destacando as tarefas fundamentais no desenvolvimento de um processo de estudo. Desse modo, o fazer matemático escolar, como um processo articulado e integrado, do tipo presente nas teorias axiomáticas, próprias da matemática, é evidenciada como essencial no processo de estudo dos objetos matemáticos, conforme o esquema abaixo.

\section{Esquema de conexões dos Tipos de Tarefas propostos para o ensino da Geometria Analítica}

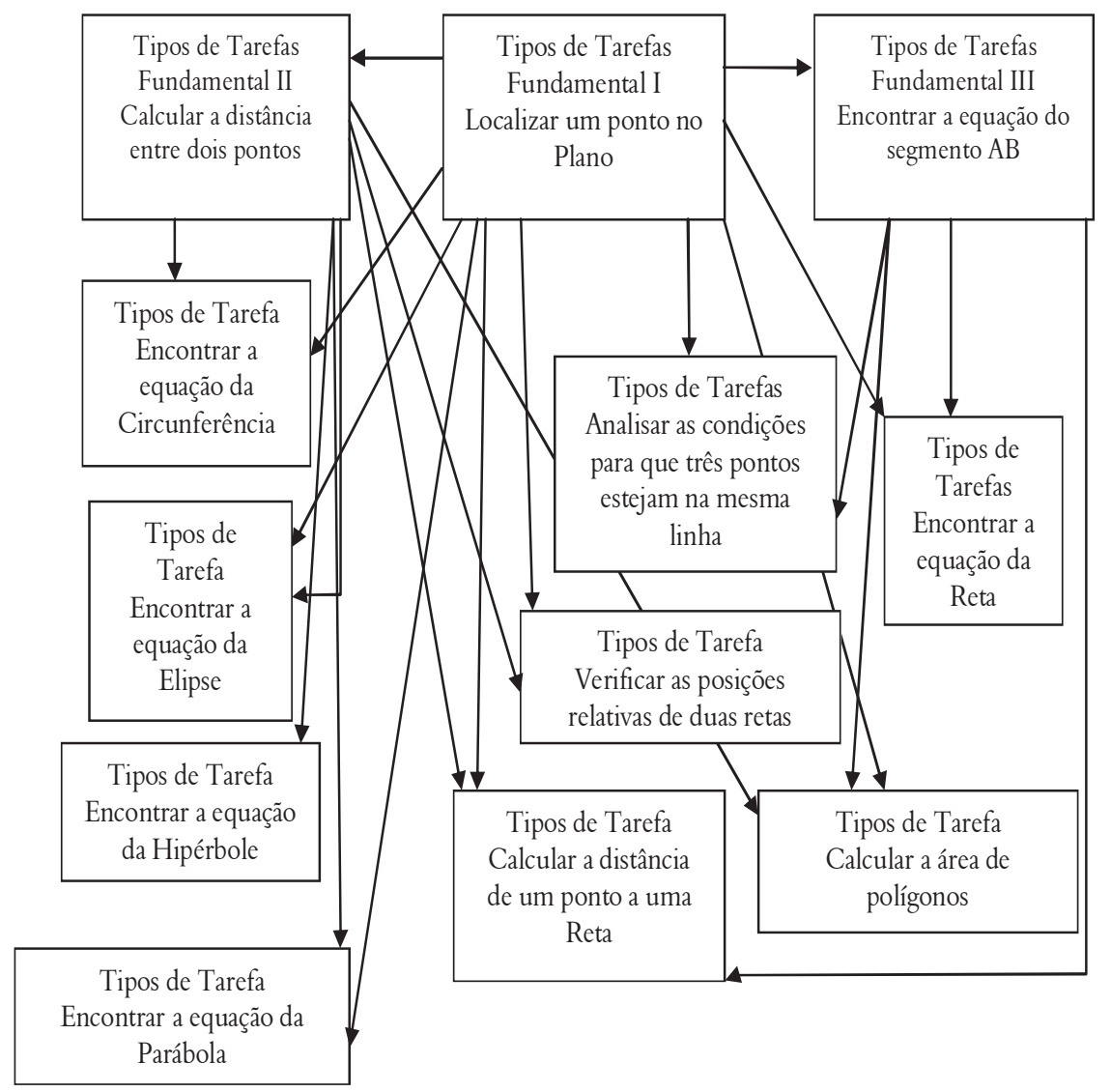




\section{Considerações finais}

Como se pode observar, as tarefas padrões estabelecidas nas organizações matemáticas da Geometria Analítica Plana, objeto de estudo do ensino médio, podem, em geral, serem entendidas como articulações e integrações de tarefas, o que permite gerar suas técnicas justificadas pelas técnicas de tarefas fundamentais. Essas tarefas, para nossa organização didática, são identificadas como Localizar um ponto no plano, Determinar a distância entre dois pontos dados, Encontrar a equação do segmento de reta, relacionadas com a tarefa Encontrar a equação da reta perpendicular a uma reta dada permitem desenvolver as principais tarefas padrões constantes dos livros didáticos, permitindo construir organizações distintas desses manuais didáticos, de tal modo que promova uma praxeologia didáticomatemática, no sentido dado pela Teoria Antropológica do Didático, que consiste num fazer articulado e integrado de tarefas/técnicas na (re)construção de novas tarefas/técnicas.

Também podemos evidenciar, nesta reflexão, o caráter funcional da técnica, da tecnologia e da teoria nas organizações didáticas que considerem as tarefas fundamentais, pois alguns tipos de tarefas podem configurar-se como técnica ou até mesmo como tecnologia para outros tipos de tarefas.

Nesse sentido, temos como indicação para trabalhos futuros investigar tarefas fundamentais presentes em outros objetos matemáticos e, ainda, a proposição das tarefas fundamentais a partir de situações adidáticas proposta pela Teoria das Situações Didáticas de Guy Brosseur. Assim, esperamos que as reflexões aqui apresentadas sirvam de subsídios a professores, nas construções de novas praxeologias didáticas, que promovam momentos didáticos do processo de estudo da Geometria Analítica Plana e que objetivem um fazer matemático escolar do aluno justificável e inteligível.

\section{REFERÊNCIAS}

ALMOULLOUD, A. S. Mr-21 A Geometria na escola básica: que espaços e formas tem hoje? In: EPEM, 7. São Paulo, 2004. Anais..., São Paulo: EPEM/USP, 2004. 10p. Disponível em: <www.sbempaulista.org. br/anais/epem > . Acesso em 25/06/2007. 
A teoria antropológica do didático. In: EBRAPEM 4. Rio Claro, 2000. Anais... Rio Claro, 2000. p. 161-169.

CHEVALLARD, Y. et al. Estudar Matemáticas: o elo entre o ensino e a aprendizagem. Trad.: Daisy Vaz de Moraes. Porto Alegre: Artes Médicas, 2001.

Organiser l'étude. 3. Écologie \& régulation. Actes de la XI école d'été de didactique. Grenoble: La Pensée Sauvage, 2002. p. 41-56.

DANTE, L. R. Matemática Volume Único. São Paulo: Ática, 2005.

MIGUEL, M. I. R. Ensino e Aprendizagem do Modelo de Poisson: uma experiência com modelagem. Tese de Doutorado em Educação Matemática. Pontifícia Universidade Católica de São Paulo, 2005.

ROSSINI, R. Saberes Docentes sobre o Tema Função: uma investigação das Praxeologias. In: Encontro Brasileiro de Estudantes de Pósgraduação em Educação Matemática 9, 2005. São Paulo. Anais... São Paulo: Feusp, 2005.

YOUSSEF, A. N. et al. Matemática: ensino médio, volume único. São Paulo: Scipione, 2005. 